\title{
Biological control of broad mites (Polyphagotarsonemus latus) with the generalist predator Amblyseius swirskii
}

\author{
Roos van Maanen · Enrico Vila $\cdot$ Maurice W. Sabelis • \\ Arne Janssen
}

Received: 1 October 2009/Accepted: 9 February 2010/Published online: 27 February 2010

(C) The Author(s) 2010. This article is published with open access at Springerlink.com

\begin{abstract}
The broad mite is a serious pest of a variety of crops worldwide. Several phytoseiid mites have been described to control these mites. However, broad mites are still one of the major pest problems on greenhouse pepper in South-eastern Spain. The generalist predatory mite $A$. swirskii is widely used against other pests of pepper plants such as thrips and whiteflies, the latter being a vector of broad mites. We assessed the potential of A. swirskii to control broad mites. The oviposition rate of A. swirskii on a diet of broad mites was lower than on a diet of pollen, but higher than oviposition in the absence of food. Population-dynamical experiments with A. swirskii on single sweet pepper plants in a greenhouse compartment showed successful control of broad mites.
\end{abstract}

Keywords Broad mites - Biological control - Sweet pepper - Western flower thrips · Greenhouse whitefly

\section{Introduction}

The broad mite, Polyphagotarsonemus latus (Banks) (Acari: Tarsonemidae), is a serious pest of several greenhouse crops worldwide, including pepper, cucumber and egg plants (Gerson 1992; Palevsky et al. 2001). Because of their small size (0.1-0.3 mm long), broad mites are not initially noticed in crops, but are detected when plants show damage symptoms (Venzon et al. 2008). Broad mites attack young, growing plant parts and oviposit on the undersides of leaf surfaces. Young pepper plants have a particular low tolerance for broad mite damage (de Coss-Romero and Peňa 1998; Jovicich et al. 2009); only five adult mites on a young pepper plant can result in lower fruit weight (Weintraub 2007).

R. van Maanen · M. W. Sabelis · A. Janssen $(\bowtie)$

Institute for Biodiversity and Ecosystem Dynamics, Science Park 904, 1098 XH Amsterdam, The Netherlands

e-mail: arne.janssen@uva.nl

E. Vila

Agrobio S.L., Ctra. Nacional 340 km. 419, 04745 La Mojonera, Almeria, Spain 
A number of phytoseid mites, such as Neoseiulus californicus (McGregor) and Neoseiulus barkeri (Hughes) have been described to offer good control of broad mites (Fan and Petitt 1994; Peña and Osborne 1996). Neoseiulus cucumeris (Oudemans) was also described to control broad mites on peppers when releasing individuals on each plant or every other plant (Weintraub et al. 2003). However, broad mites are still one of the major pests on greenhouse peppers in south-eastern Spain (E. Vila personal observation). This is mainly due to high temperatures and low humidity during summers in this region and the prevalence of whiteflies, the vector of broad mites (Parker and Gerson 1994).

This paper reports on a candidate natural enemy for biological control of broad mites, the generalist predatory mite Amblyseius swirskii (Athias-Henriot) (Acari: Phytoseiidae). It has been shown capable of suppressing populations of the tobacco whitefly [Bemisia tabaci (Gennadius)], the greenhouse whitefly [Trialeurodes vaporariorum (Westwood)] (Hemiptera: Aleyrodidae) and the Western flower thrips [Frankliniella occidentalis (Pergande)] (Nomikou et al. 2001, 2002; Messelink et al. 2006, 2008). Currently, A. swirskii is widely used to control thrips and whiteflies (vector of broad mites) in sweet pepper crops, also in South-eastern Spain. In order to establish the suitability of A. swirskii to control broad mites, we measured oviposition and predation on broad mites in the laboratory and tested the ability of $A$. swirskii to control broad mites on pepper plants in a greenhouse.

\section{Materials and methods}

Sweet pepper plants were grown, pesticide free, in pots $(2 \mathrm{~L})$ with potting soil (Jongkind $\mathrm{BV}$, Aalsmeer, Hol03/No.3) in a greenhouse compartment $(3 \times 7 \mathrm{~m})$. Amblyseius swirskii was reared on plastic arenas $(8 \times 15 \mathrm{~cm})$, placed on a wet sponge in a plastic tray containing water (Nomikou et al. 2003). They were fed cattail pollen, Typha latifolia L., provided twice per week. Broad mites were collected in Almería, Spain. Females were collected from infested pepper leaves with a fine brush, and a culture was started on intact pepper plants, which were grown as above, but kept in a box made of glass $(45 \times 45 \times 55 \mathrm{~cm})$ inside a walk-in climate room $\left(25^{\circ} \mathrm{C} \pm 1.5\right.$ and $60 \% \pm 0.5$ humidity), free of other herbivores.

\section{Oviposition and predation}

The oviposition and predation rate of $A$. swirskii were measured during 2 days on a diet of adult female broad mites. Adult female broad mites are larger than adult males and relatively easy to detect. As a control, we measured oviposition rates without food and on a diet of pollen, which is known to be a good food source for this predator (Nomikou et al. 2002).

Young adult female predators (8-9 days old since the egg stage) were tested individually on a pepper plant leaf disc (diam. $24 \mathrm{~mm}$ ) with a supply of 15 broad mites per leaf disc per day. A pilot study showed that this density is high enough to ensure maximum prey consumption. Predation was recorded as the number of broad mites consumed (as judged by the presence of the remaining transparent cuticles) after 24 and $48 \mathrm{~h}$. Because oviposition rates are affected by the previous food source of adult predatory mites, we used oviposition data from the second day of the experiment only (Sabelis 1990). The distribution of oviposition data was non-normal due to zero inflation (especially in the treatment without food), even after transformations; we therefore used the more conservative nonparametric Kruskal-Wallis test with post-hoc comparisons (Siegel and Castellan 1988) to compare oviposition among diets. 
Broad mite control on sweet pepper plants

The capacity of $A$. swirskii to control populations of broad mites was tested on sweet pepper plants in a greenhouse. The experiment was conducted from March to May, 2008. Young plants without flowers were used because they produce no pollen that could be used as food by the predatory mites. Plants were cultivated until reaching a height of $20-30 \mathrm{~cm}$ with 10-20 leaves. Twenty or forty adult female broad mites, collected from the culture with a fine brush, were released on each plant. After $1 \mathrm{~h}$, two females of A. swirskii were released on each plant, except for the controls. This resulted in four initial predator: prey ratios; $0: 10 ; 0: 20 ; 1: 10$ and 1:20, ratios were replicated four to seven times. Contamination of the plants with other herbivores was avoided by keeping the plant pots isolated in a water layer on tables inside the greenhouse compartments. The greenhouse compartments were free from flying herbivores such as whiteflies during the whole experiment. The replicates of different treatments of the experiment were performed in two different greenhouse compartments.

The experiment lasted for 3 weeks. During this period, the plants were watered twice a week. The average temperature and relative humidity were similar for each treatment $\left(25^{\circ} \mathrm{C} \pm 1.5\right.$ and $60 \% \pm 0.5$ humidity). The numbers of predatory mites and broad mites were assessed 3 weeks after introduction of the mites by collecting all leaves from each plant of each treatment. The leaves of each plant were put in a separate plastic bag and stored in a freezer. Later, they were cut into strips of $5 \mathrm{~cm}$ and the number of all stages of predatory mites and adult female broad mites was counted using a binocular microscope (magnification $40 \times$ ). For similar reasons as given above, we reverted to Kruskal-Wallis ANOVAs (Siegel and Castellan 1988) to test for differences among treatments.

\section{Results}

Oviposition and predation

Oviposition was significantly different among treatments (Fig. 1, KW $=44.4, d f=2$, $P<0.0001$ ). The oviposition rate of $A$. swirskii on a diet of broad mites was lower than the oviposition rate on a diet of pollen (difference in average rank $=14.9, P<0.05$ ), but higher than oviposition in the absence of food (difference in average rank $=36.9$, $P<0.0005$, Fig. 1). The predators consumed on average $8.6(\mathrm{SE}=0.80)$ adult female broad mites per female during the first day and $10.2(\mathrm{SE}=0.70)$ during the second day.

Broad mite control on sweet pepper plants

Amblyseius swirskii was very effective at controlling populations of broad mites (Fig. 2). There was a significant effect of the initial predator-prey ratio on the numbers of broad mites at the end of the experiment $(\mathrm{KW}=12.7, d f=3, P=0.0053)$. There was no significant difference in broad mite densities on plants without predators (difference in average rank $=3.75, P>0.05$ ). Also, the density of broad mites did not differ significantly between the two treatments with predators (difference in average rank $=4.2$, $P>0.05)$. This is probably due to the large variation between plants within the treatment with initial ratio $1: 10$. Sweet pepper plants without predatory mites had significantly more broad mites than sweet pepper plants with predatory mites $(\mathrm{KW}=12.7, d f=1$, $P=0.0015)$. The release of predatory mites resulted in successful control of broad mites 
Fig. 1 Average oviposition rate of young adult Amblyseius swirskii on a diet of broad mites, pollen or without food. Shown are average numbers of eggs $(+$ SEM) per female per day measured from 24 to $48 \mathrm{~h}$ since the predators were put on the diet or kept without food. Different letters indicate significant differences among treatments
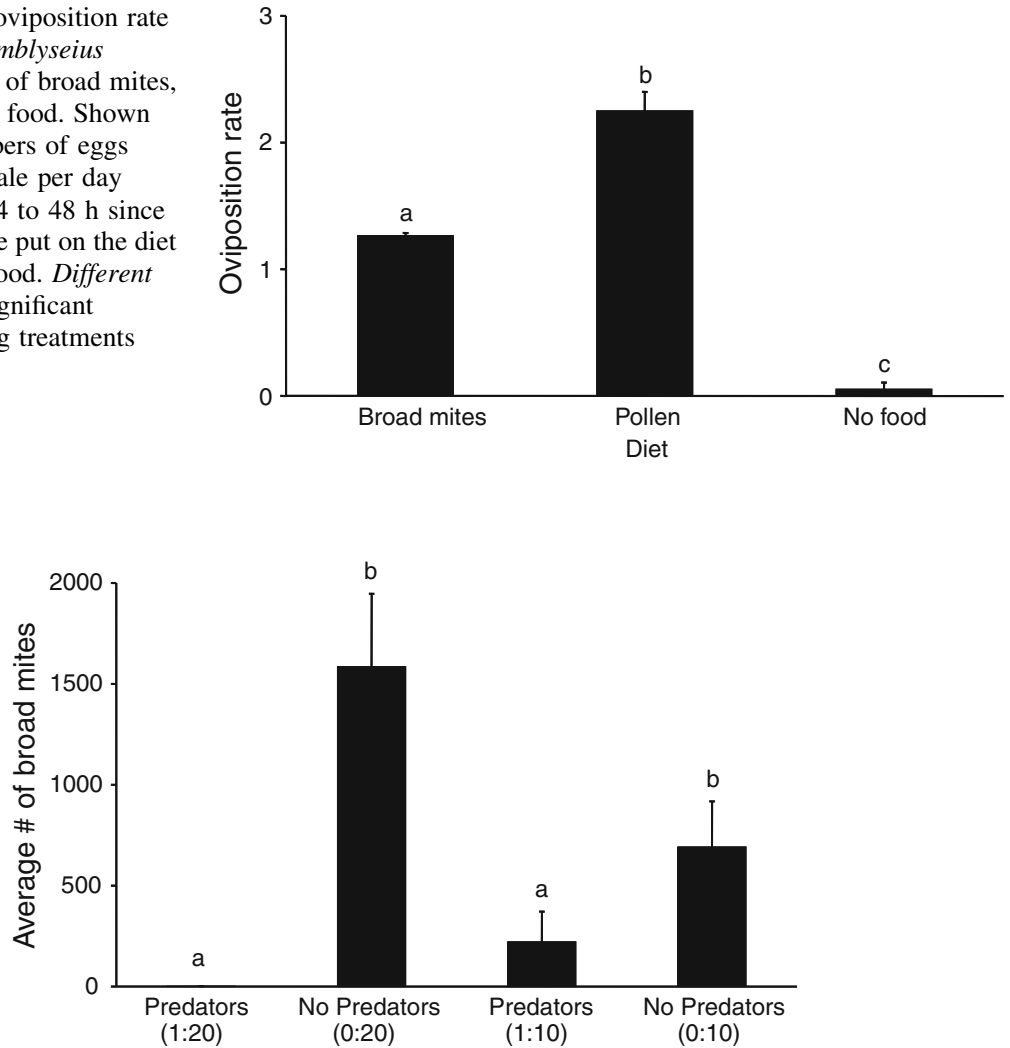

Fig. 2 Average number of Polyphagotarsonemus latus females (+SEM) per plant, 3 weeks after introducing broad mites and predators simultaneously (1:20 means 40 females of $P$. latus were introduced with 2 Amblyseius swirskii females; 1:10 means 20 P. latus females were introduced with 2 A. swirskii). Different letters indicate significant differences among treatments

(fewer than 4 broad mites per plant) on plants with an initial ratio 1:20. After 3 weeks, the average number of predators per plant did not differ between the two treatments with predators $(\mathrm{KW}=0.135, d f=1, P=0.71)$.

\section{Discussion}

We studied the ability of a generalist predatory mite to control broad mites on sweet pepper plants. Although the predators produced fewer eggs per day when offered a diet of broad mites compared to a diet of pollen, they successfully controlled broad mites on greenhousegrown sweet pepper plants with an initial predator: prey ratio of 1:20 (fewer than 4 broad mites per plant after 3 weeks). Although the oviposition of A. swirskii on a diet of broad mites is not as high as on other arthropods food sources, such as thrips larvae or whitefly eggs (Messelink et al. 2008), we expect an effective control of broad mites in greenhouses for two reasons.

1. The predatory mites are generalists and prey on eggs of whiteflies. Broad mites often co-occur with whiteflies because adult whiteflies are vectors of broad mites 
(Natarajan 1988; Flechtmann et al. 1990). By feeding on whitefly eggs, the predator will decrease the future vector population, thus reducing the dispersion of broad mites.

2. Besides feeding on broad mites and whiteflies, A. swirskii also feeds and reproduces on thrips and pollen and can therefore be released preventively in the crop. Because a few individual broad mites can lead to substantial damage of sweet pepper plants, preventive release of biological control agents is required.

Our results demonstrate the potential of Amblyseius swirskii to control broad mites on sweet pepper plants. However, large greenhouse experiments are necessary to confirm its efficacy in reducing $P$. latus under commercial growth conditions. Furthermore, experiments are needed to study the control of broad mites in the presence of whiteflies and other food sources for the predators (Messelink et al. 2008; Nomikou et al. 2010). If, for example, $A$. swirskii has a strong preference for feeding on whiteflies over broad mites, this could lead to temporarily reduced predation in the presence of whiteflies, but at the same time to reduced dispersal of broad mites through phoresy on whiteflies.

Acknowledgments RvM received a scholarship of the Technology Foundation (STW Project 7180). Nicola Tien is acknowledged for many useful comments and stimulating discussions. The comments of two anonymous reviewers was greatly appreciated.

Open Access This article is distributed under the terms of the Creative Commons Attribution Noncommercial License which permits any noncommercial use, distribution, and reproduction in any medium, provided the original author(s) and source are credited.

\section{References}

de Coss-Romero M, Peňa JE (1998) Relationship of broad mite (Acari: Tarsonemidae) to host phenology and injury levels in Capsicum annuum. Fla Entomol 81:515-526

Fan Y, Petitt FL (1994) Dispersal of the broad mite, Polyphagotarsonemus latus (Acari: Tarsonemidae) on Bemisia argentifolii (Homoptera: Aleyrodidae). Exp Appl Acarol 22:411-415

Flechtmann CHW, Guerrero JM, Arroyave JA, Constantino CLM (1990) A little known mode of dispersal of Polyphagotarsonemus latus (Banks). Int J Acarology 16:181-182

Gerson U (1992) Biology and control of the broad mite, Polyphagotarsonemus latus (Banks) (Acari, Tarsonemidae). Exp Appl Acarol 13:163-178

Jovicich E, Cantliffe DJ, Osborne LS, Stoffella PJ, Simonne EH (2009) Release of Neoseiulus californicus on pepper transplants to protect greenhouse-grown crops from early broad mite (Polyphagotarsonemus latus) infestations. In: Mason PG, David R (eds) Proceedings of the Third International Symposium on Biological Control of Arthropods. Christchurch, New Zealand

Messelink GJ, van Steenpaal SEF, Ramakers PMJ (2006) Evaluation of phytoseiid predators for control of Western flower thrips on greenhouse cucumber. Biocontrol 51:753-768

Messelink GJ, van Maanen R, van Steenpaal SEF, Janssen A (2008) Biological control of thrips and whiteflies by a shared predator: two pests are better than one. Biol Control 44:372-379

Natarajan K (1988) Transport of yellow mite Polyphagotarsonemus latus by cotton whitefly. Curr Sci 57:1142-1143

Nomikou M, Janssen A, Schraag R, Sabelis MW (2001) Phytoseiid predators as potential biological control agents for Bemisia tabaci. Exp Appl Acarol 25:271-291

Nomikou M, Janssen A, Schraag R, Sabelis MW (2002) Phytoseiid predators suppress populations of Bemisia tabaci on cucumber plants with alternative food. Exp Appl Acarol 27:57-68

Nomikou M, Janssen A, Sabelis MW (2003) Phytoseiid predators of whiteflies feed and reproduce on nonprey food sources. Exp Appl Acarol 31:15-26

Nomikou M, Sabelis MW, Janssen A (2010) Pollen subsidies promote whitefly control through the numerical response of predatory mites. BioControl (in press). doi:10.1007/s10526-009-9233-X

Palevsky E, Soroker V, Weintraub P, Mansour F, Abo-Moch F, Gerson U (2001) How species-specific is the phoretic relationship between the broad mite, Polyphagotarsonemus latus (Acari: Tarsonemidae), and its insect hosts? Exp Appl Acarol 25:217-224 
Parker R, Gerson U (1994) Dispersal of the broad mite, Polyphagotarsonemus latus (Banks) (Heterostigmata: Tarsonemidae), by the greenhouse whitefly, Trialeurodes vaporariorum (Westwood) (Homoptera: Aleyrodidae). Exp Appl Acarol 18:581-585

Peña JE, Osborne L (1996) Biological control of Polyphagotarsonemus latus (Acarina: Tarsonemidae) in greenhouses and field trials using introductions of predacious mites (Acarina: Phytoseiidae). Entomophaga 41:279-285

Sabelis M (1990) How to analyze prey preference when prey density varies - a new method to discriminate between effects of gut fullness and prey type composition. Oecologia 82:289-298

Siegel S, Castellan NJ (1988) Nonparametric Statistics for the Behavioral Sciences, 2nd Edition. McGrawHill, New York

Venzon M, Rosado MC, Molina-Rugama AJ, Duarte VS, Dias R, Pallini A (2008) Acaricidal efficacy of Neem against Polyphagotarsonemus latus (Banks) (Acari : Tarsonemidae). Crop Prot 27:869-872

Weintraub PG (2007) Integrated control of pests in tropical and subtropical sweet pepper production. Pest Manag Sci 63:753-760

Weintraub PG, Kleitman S, Mori R, Shapira N, Palevsky E (2003) Control of broad mite (Polyphagotarsonemus latus (Banks)) on organic greenhouse sweet peppers (Capsicum annuum L.) with the predatory mite, Neoseiulus cucumeris (Oudemans). Biol Control 27:300-309 